\title{
Beneficial effects of consumption of acerola, cashew or guava processing by-products on intestinal health and lipid metabolism in dyslipidaemic female Wistar rats
}

\author{
Kamila Sabino Batista ${ }^{1}$, Adriano Francisco Alves ${ }^{2}$, Marcos dos Santos Lima ${ }^{3}$, Laiane Alves da Silva ${ }^{1}$, \\ Priscilla Paulo Lins ${ }^{1}$, Jéssyca Alencar de Sousa Gomes ${ }^{1}$, Alexandre Sérgio Silva ${ }^{4}$, Lydiane Tavares Toscano ${ }^{4}$, \\ Bruno Raniere Lins de Albuquerque Meireles ${ }^{5}$, Angela Maria Tribuzy de Magalhães Cordeiro ${ }^{6}$, \\ Maria Lúcia da Conceição ${ }^{1}$, Evandro Leite de Souza ${ }^{1}$ and Jailane de Souza Aquino ${ }^{1 *}$ \\ ${ }^{1}$ Departamento de Nutrição, Universidade Federal da Paraíba, João Pessoa 58051-900, Paraíba, Brazil \\ ${ }^{2}$ Departamento de Patologia, Universidade Federal de Minas Gerais, Belo Horizonte 31270-901, Minas Gerais, Brazil \\ ${ }^{3}$ Departamento de Tecnologia de Alimentos, Instituto Federal do Sertão de Pernambuco, Petrolina 56.314-520, Pernambuco, Brazil \\ ${ }^{4}$ Departamento de Educação Física, Universidade Federal da Paraíba, João Pessoa 58051-900, Paraíba, Brazil \\ ${ }^{5}$ Departamento de Engenharia de Alimentos, Unidade Acadêmica de Tecnologia de Alimentos, Universidade Federal de \\ Campina Grande, Pombal 58840-000, Paraíba, Brazil \\ ${ }^{6}$ Departamento de Tecnologia de Alimentos, Centro de Tecnologia e Desenvolvimento Regional, Universidade Federal da \\ Paraíba, João Pessoa 58051-900, Paraíba, Brazil
}

(Submitted 14 July 2017 - Final revision received 16 October 2017 - Accepted 26 October 2017)

\section{Abstract}

This study assessed the effects of diet supplementation with industrial processing by-products of acerola (Malpighia emarginata D.C.), cashew (Anacardium occidentale L.) and guava (Psidium guajava L.) fruit on the intestinal health and lipid metabolism of female Wistar rats with diet-induced dyslipidaemia. Female rats were randomly divided into five groups: healthy control, dyslipidaemic control and dyslipidaemic experimental receiving acerola, cashew or guava processing by-products. Fruit processing by-products were administered ( $400 \mathrm{mg} / \mathrm{kg}$ body weight) via orogastric administration for 28 consecutive days. Acerola, cashew and guava by-products caused body weight reduction (3.42, 3.08 and 5.20\%, respectively) in dyslipidaemic female rats. Dyslipidaemic female rats receiving fruit by-products, especially from acerola, presented decreased faecal $\mathrm{pH}$, visceral fat, liver fat and serum lipid levels, as well as increased faecal moisture, faecal fat excretion, faecal Bifidobacterium spp. and Lactobacillus spp. counts and amounts of organic acids in faeces. Administration of the tested fruit processing by-products protected colon and liver from tissue damage (e.g. destruction of liver and colon cells and increased fat deposition in hepatocytes) induced by dyslipidaemic diet. Dietary fibres and phenolic compounds in tested fruit by-products may be associated with these positive effects. The industrial fruit processing by-products studied, mainly from acerola, exert functional properties that could enable their use to protect the harmful effects on intestinal health and lipid metabolism caused by dyslipidaemic diet.

Key words: By-products: Dyslipidaemia: Fibres: Intestinal microbiota

Excessive intake of dietary trans-fat, saturated fat and cholesterol induces changes in lipid metabolism and leads to dyslipidaemia, which is one of the most prevalent chronic noncommunicable diseases worldwide. Dyslipidaemia results from changes in lipid metabolism, being characterised by increased plasma levels of total cholesterol (TC), LDL and TAG and reduced levels of HDL. These may or may not occur simultaneously ${ }^{(1)}$. Furthermore, excessive dietary fat may lead to the accumulation of fat in the liver (liver steatosis) ${ }^{(2)}$ that predisposes to the development of non-alcoholic fatty liver disease (NAFLD) ${ }^{(3)}$ and atherosclerotic CVD (ACD) ${ }^{(4,5)}$.

Regular ingestion of fruit and dietary fibre (DF) has been recommended as primary prevention or treatment strategy for dyslipidaemia $^{(6,7)}$, NAFLD and $\mathrm{ACD}^{(8,9)}$. Acerola (Malpighia emarginata D.C.), cashew (Anacardium occidentale L.) and guava (Psidium guajava L.) are tropical fruits consumed 'in natura' or processed to produce mostly juices and frozen pulp $^{(10-12)}$. Agro-industrial processing of these fruits generates a

Abbreviations: DC, non-treated dyslipidaemic control; DEA, dyslipidaemic group supplemented with acerola by-product; DEC, dyslipidaemic group supplemented with cashew by-product; DEG, dyslipidaemic group supplemented with guava by-product; DF, dietary fibre; HC, healthy control; IDF, insoluble dietary fibre; SDF, soluble dietary fibre; TC, total cholesterol.

*Corresponding author: J. d. S. Aquino, fax +55 83 32167094, email aquinojailane@gmail.com; jailane@ccs.ufpb.br 
large amount of by-products (such as, peel, seeds and flesh) that if inappropriately discarded cause damage to the environment, requiring high costs to reduce their negative impacts ${ }^{(13)}$.

Use of fruit industrial processing by-products in the human diet should be an interesting alternative destination because some of these materials contain high amounts of DF, as observed in by-products generated from acerola (37.32-80.42 g/100 g dry basis $)^{(14)}$, cashew $(76.20 \mathrm{~g} / 100 \mathrm{~g} \text { dry basis) })^{(15)}$ and guava $(88.7 \mathrm{~g} /$ $100 \mathrm{~g}$ dry basis) processing ${ }^{(16)}$. In addition, high amounts of total phenolics have been observed in processing industrial by-products of acerola $(7265.29 \mathrm{mg}$ gallic acid equivalents (GAE)/100 g dry basis), cashew (6588.41 mg GAE/100 g dry basis) and guava $\left(1987 \cdot 19 \mathrm{mg}\right.$ GAE$/ 100 \mathrm{~g}$ dry basis ${ }^{(17)}$. Consumption of DF may modulate the composition of intestinal microbiota and fermentation activity of beneficial bacteria (e.g. Bifidobacterium and Lactobacillus) found there ${ }^{(18,19)}$, increasing the production of SCFA that contribute to the maintenance of intestinal health ${ }^{(20)}$. Phenolic compounds have been also associated with positive effects on intestinal microbiota composition and SCFA production ${ }^{(21-23)}$. SCFA are saturated aliphatic organic acids exerting positive effects on intestinal and liver health and function, as well as on the regulation of lipid metabolism ${ }^{(24-26)}$.

This study evaluated whether the consumption of by-products generated from industrial processing of acerola, cashew and guava can affect selected parameters that indicate the intestinal health and lipid metabolism of female Wistar rats with induced dyslipidaemia.

\section{Methods}

\section{Acquisition and preparation of fruit processing by-products}

By-products, mostly composed of mashed peels and seeds and small amount of flesh, generated from acerola, cashew and guava industrial processing were obtained from a fruit pulp processing industry (Polpa Ideal Indústria Ltda). The by-products were homogenised after freezing in liquid $\mathrm{N}_{2}$ and freeze-dried $\left(-40^{\circ} \mathrm{C}\right.$, vacuum pressure $\left.<150 \mu \mathrm{mHg}\right)$ for approximately $12 \mathrm{~h}$ in a bench lyophilizer model L-101 (LIOTOP). The freeze-dried material obtained was ground in a domestic blender, sieved through a $1 \cdot 0-\mathrm{mm}$ mesh and stored $\left(-10^{\circ} \mathrm{C}\right)$ in glass containers under light protection.

Moisture, ash, protein and lipid content and the total energy value $^{(27)}$ of these freeze-dried by-products were analysed in triplicate; total, soluble (SDF) and insoluble DF (IDF), respectively, were measured using an enzymatic-gravimetric method $^{(28)}$, and fructan content was measured by enzymatic hydrolysis ${ }^{(27)}$. Organic acids, sugars and phenolic contents were determined by HPLC under analytical conditions described elsewhere $^{(29)}$. Nutritional composition and amounts of different phenolic compounds in freeze-dried acerola, cashew and guava processing by-products used in this study are shown in Table 1.

\section{Animals}

In all, forty female adult Wistar rats, approximately $90 \mathrm{~d}$ old, were maintained individually in metabolic cages with water and food ad libitum at $21 \pm 1^{\circ} \mathrm{C}$, relative humidity in the range of $50-55 \%$ and alternating $12 \mathrm{~h}$ light- $12 \mathrm{~h}$ dark cycles. The experimental protocol used in this study was approved by a Committee on Ethics in Animal Experimentation (Center of Biotechnology, Federal University of Paraíba, João Pessoa, Brazil) under the no. 0505/14. All experiments were performed in agreement with the guidelines of Brazilian College for Animal Experimentation (COBEA, Brazil).

\section{Experimental design}

After an acclimatisation period of 1 week, the female Wistar rats were randomly put into five groups: a healthy control group (HC, $n$ ), which received saline solution via gavage and was fed on an AIN 93M diet ${ }^{(30)}$ (Rhoster) throughout the experiment; a dyslipidaemic control group (DC, $n$ 8), which received saline solution via gavage and was fed on a dyslipidaemic diet (Rhoster), containing 6\% lard, 5\% non-hydrolysed vegetable fat, $1 \%$ cholesterol and $0.5 \%$ cholic acid (online Supplementary Table S1), throughout the experiment; and three dyslipidaemic experimental groups that were fed a dyslipidaemic diet throughout the experiment and received supplementation with processing by-products of acerola (DEA, $n$ 8), cashew (DEC, $n$ 8) or guava (DEG, $n$ ).

Initially, the female rats forming the dyslipidaemic groups (DC, DEA, DEC and DEG) had undergone previous treatment by consuming a dyslipidaemic diet for 2 weeks ${ }^{(31)}$. After this period, the detection of dyslipidaemia was performed through biochemical examination of the lipid profile in all groups (online Supplementary Table S2). Afterwards, the female rats forming HC and DC groups received a saline solution via gavage for 28 consecutive days, and those forming the DEA, DEC and DEG groups received acerola, cashew or guava processing by-product at a dose of $400 \mathrm{mg} / \mathrm{kg}$ body weight (fruit by-products were diluted $(1.6 \%, \mathrm{w} / \mathrm{v})$ in saline solution), respectively, via gavage $^{(32)}$ for the same time period. Gavage was performed twice a day at 4-h intervals in the morning and afternoon periods. Body weight and food consumption were assessed weekly.

On day 29 of treatment, the animals were fasted for $12 \mathrm{~h}$ and then anaesthetised by intraperitoneal injection of $1 \mathrm{ml}$ of ketamine hydrochloride $(75 \mathrm{mg}$ ) and $1 \mathrm{ml}$ of xylazine hydrochloride $(5 \mathrm{mg})$ per kg body weight. Following the euthanasia of animals via aortic transection, visceral fat samples were collected and weighed. Colon and liver were removed for histological analysis and faeces were collected from caecum for microbiological counts and quantification of organic acids and total fat. Serum was collected and maintained at room temperature $\left(25 \pm 1^{\circ} \mathrm{C}\right)$ for determination of lipid profile.

\section{Determination of lipid profile}

Serum concentrations of TC and HDL were measured using the Trinder enzymatic method and the accelerator selective detergent method using Liquiform Cholesterol and HDL LE kits, respectively (Labtest). TAG levels were determined using the Trinder method with a TAG Liquiform kit (Labtest). All analyses followed the manufacturer's recommendations, and absorbance was determined using a LabMax 240 Premium automatic analyser (Labtest) at $505 \mathrm{~nm}$ (TAG), $500 \mathrm{~nm}$ (TC) or $600 \mathrm{~nm}$ (HDL). LDL and VLDL values were calculated using previously described equations ${ }^{(33)}$, as follows: $\mathrm{LDL}=\mathrm{TC}-\mathrm{HDL}-\mathrm{TAG} / 5$; and $\mathrm{VLDL}=\mathrm{TAG} / 5$. 
Fat in liver and moisture, $\mathrm{pH}$, fat and microbial counts in faeces

For three consecutive days, that is, on days 26, 27 and 28 of treatment, faecal samples were collected and stored at $-20^{\circ} \mathrm{C}$. For analysis, the samples were diluted in deionised water $(1 \mathrm{mg} / \mathrm{ml})$ and faecal $\mathrm{pH}$ was measured using a digital potentiometer (Q400AS; Quimis) ${ }^{(34)}$. A separate portion of faecal sample was dried in an oven $\left(320-\mathrm{SE}\right.$; Fanem) at $105^{\circ} \mathrm{C}$ for $24 \mathrm{~h}$ to determine faecal moisture ${ }^{(27,35)}$.

Another portion of faecal samples collected from caecum was diluted (1:9) in sterile peptone water and inoculated $(20 \mu \mathrm{l})$, using the microdrop technique ${ }^{(36)}$, on selective agar for counting Lactobacillus spp. (de Man, Rogosa and Sharpe (MRS); HiMedia), Bifidobacterium spp. (Bifidobacterium agar; HiMedia) and Enterobacteriaceae (MacConkey agar; HiMedia). Agar plates for counting Lactobacillus spp. and Bifidobacterium spp. were incubated under anaerobic conditions (Anaerobic System Anaerogen; Oxoid Ltd) and agar plates for counting Enterobacteriaceae were incubated under aerobic conditions, all at $37^{\circ} \mathrm{C}$ for $24-48 \mathrm{~h}$. At the end of the incubation period, characteristic colonies on the selective media were counted, and the results were expressed as log of colony-forming units per $\mathrm{g}$ of faeces $\left(\log _{10} \mathrm{CFU} / \mathrm{g}\right)^{(37)}$. Total lipid in faeces and liver was determined by cold extraction ${ }^{(38)}$.

\section{Quantification of organic acids in faeces}

Contents of acetic, butyric, propionic, formic, citric, lactic and malic acids in faeces were quantified by HPLC using a 1260 Infinity LC system (Agilent Technologies) coupled to a PDA detector (G1315D; Agilent Technologies). For analysis, an Agilent Hi-Plax $\mathrm{H}(300 \times 7.7 \mathrm{~mm})$ column with $8.0 \mu \mathrm{m}$ particle size was used; the column was protected with a PL Hi-Plax $\mathrm{H}(5 \times 3 \mathrm{~mm})$ guard column (Agilent Technologies). Column temperatures were maintained at $50^{\circ} \mathrm{C}$. Each sample was diluted in ultrapure water filtered through a $0.45-\mu \mathrm{m}$-pore membrane, with an injection volume of $10 \mu \mathrm{l}$, at a flow rate of $0.5 \mathrm{ml} / \mathrm{min}$ and a runtime of $20 \mathrm{~min}$. The phase was $4.0 \mathrm{~mm} \mathrm{H}_{2} \mathrm{SO}_{4}$ in ultrapure water. Obtained data were processed using Open LAB CDS Cessation Edition (Agilent Technologies). HPLC sample peaks were identified by comparing their retention times with those of organic acid standards ${ }^{(39)}$. Duplicate injections were performed, and average peak areas were used for quantification. Standard of formic acid was obtained from Sigma-Aldrich, and standards of acetic, butyric, propionic, citric, lactic and malic acids were obtained from Vetec, all with a purity of $\geq 99 \%$. Ultrapure water was obtained from a Mille ${ }^{\circledR}$ system (EMD Millipore), and sulphuric acid was obtained from Merck.

\section{Histopathological evaluation of the intestine and liver}

Colon and liver fragments were excised, washed in saline solution $(0.9 \% \mathrm{NaCl})$, fixed in $10 \%$ buffered formalin for $48 \mathrm{~h}$ and subjected to histological processing. Samples were dehydrated in an increasing ethanol series, clarified in xylene, embedded in paraffin and sectioned in a microtome to obtain $5 \mu \mathrm{m}$-thick slices. Sections were stained with haematoxylin-eosin (H\&E) and periodic acidSchiff (PAS) and analysed under a light microscope (Motif BA 200) at $4 \times, 10 \times, 20 \times$ and $40 \times$ magnifications. Morphological analysis of the intestine included evaluation of inflammatory processes presence, such as stasis, leucocyte migration, haemorrhage, vasodilation and necrosis, as well as evaluation of epithelial preservation, hypertrophy and hyperplasia of the outer muscular layer. The morphological analysis of liver included evaluation of the occurrence of degenerative processes by fatty degeneration and inflammatory parameters, including leucocyte migration, oedema, hyperaemia, haemorrhage, necrosis, preservation of liver parenchyma and presence of microthrombi.

\section{Statistical analysis}

Statistical power of $0 \cdot 80$ (80\%) was obtained by estimating forty adult female Wistar rats (eight females per group) when the minimally detectable effect size was 1.0 and the significance level was 0.05. Food intake, body weight and lipid intake data were compared by a two-way ANOVA for independent measures with a factor for group (five levels) and a factor for time (four or five levels). Other data with single factor for group were analysed via one-way ANOVA. When there was a difference between the obtained data, Tukey's post hoc test was performed at a significance level of $5 \%(P \leq 0 \cdot 05)$. Results are expressed as the means and standard deviations. The software SigmaPlot 12.5 for Windows (Systat Software Inc.) was used to perform the statistical analysis and graphic design.

\section{Results and discussion}

\section{Food intake and body weight}

Food intake and body weight of the HC, DC, DEA, DEC and DEG groups were monitored during the 28-d experimental period (online Supplementary Fig. S1(a) and S1(b)). The HC group presented the highest food consumption during the monitored period $(P \leq 0.05)$ when compared with the other groups. DEA, DEC, DEG and DC groups presented similar food consumption over time $(P>0.05)$, with exception of the DEA group that presented lower food consumption than the HC group during the 1 st week of the experimental period $(P \leq 0.05)$. These results indicate that the dyslipidaemic diet consumption promoted greater satiety ${ }^{(40,41)}$ in the DEA, DEC, DEG and DC groups. The fruit by-products tested had little influence on the appetite of the animals, probably owing to the lower energy value provided by DF, which was detected in high amounts in these materials. These findings are similar to those found in a previous study that administered different amounts of prebiotic fibres in diet, and observed no difference in diet intake among the groups of animals receiving these fibres ${ }^{(42)}$.

Although consuming a high-lipid and high-energy diet (online Supplementary Table S1 and Supplementary Fig. S1(c)), the DC group showed body weight gain similar to HC group $(P>0.05)$, which could be related to a lower dyslipidaemic diet intake by the DC group during the experimental period. Short-term dietary fat consumption is associated with satietyinducing intestinal peptides expression, such as cholecystokinin, glucagon-like peptide-1, pancreatic polypeptide, peptide YY and oxymomodulin. Interestingly, these effects are attenuated with long-term dietary fat consumption ${ }^{(40,41)}$. 
DEA, DEC and DEG groups showed body weight loss during the monitored experimental period $(P \leq 0.05)$. Body weight loss among these groups followed the order DEG $>$ DEA $>$ DEC. Although the DEA, DEC and DEG groups consumed an amount of dyslipidaemic diet similar to the DC group, the DF of the fruit by-products contributed to the weight loss of the animals, as the consumption of the tested fruit by-products may have facilitated greater faecal excretion of dietary fat, implying i) lower energy absorbed and metabolised; ii) increased postprandial energy expenditure by favouring greater gastrointestinal motility; and iii) increased excretion of bile acids, inducing the mobilisation of body fat reserves for the bile acids hepatic synthesis ${ }^{(43)}$. A previous study found that high-fat-diet consumption resulted in increased body weight in rats over time, whereas the same high-fat diet to which had been added $10 \%$ dehydrated guava reduced rats' body weight gain ${ }^{(44)}$. Consumption of acerola juice has shown to be effective in preventing body weight gain in mice fed a cafeteria $\operatorname{diet}^{(45)}$.

\section{Effects on lipid profile}

The DC group exhibited higher TC, TAG and LDL levels compared with the HC, DEA, DEC and DEG groups $(P \leq 0.05)$ (Fig. 1(a), (b) and (d)). The DEA and DEG groups presented lower VLDL levels compared with the DC group $(P \leq 0.05)$ (Fig. 1(e)). The DEA and DEC groups presented increases in HDL levels (Fig. 1(c)) by 104.96 and $40.74 \%$, respectively, compared with the DC group $(P \leq 0.05)$.
An increase in HDL levels is associated with increased protection against atherosclerosis, whereas an increase in LDL levels is associated with increased atherosclerosis risks. Similarly, high cholesterol and VLDL serum levels indicate a higher atherogenic risk $^{(7,46)}$. Considering the results of this study, consumption of acerola, cashew and guava by-products, particularly the acerola by-product, was effective in preventing changes in lipid metabolism induced by the dyslipidaemic diet.

Improvement in lipid profile of dyslipidaemic animals receiving fruit processing by-products could be related to the fibre content and phenolic compounds (Table 1) found in these materials. SDF increases intraluminal viscosity, affects the enterohepatic circulation of bile acids and reduces fat absorption ${ }^{(47)}$. Phenolic compounds increase bile acids excretion and inhibit fat and cholesterol intestinal absorption by modulating expression and interacting with the intestinal cholesterol transporter NiemannPick C1-Like 1, which prevent the absorption of dietary cholesterol $^{(48,49)}$. Excretion of bile acids in faeces induces the production of bile via cholesterol in the liver, lowering cholesterol plasma levels and cholesterol-transporting lipoproteins ${ }^{(50)}$.

\section{Effects on pH, moisture, organic acids and microbial counts in faeces}

The DC group showed a higher faecal $\mathrm{pH}$ than the HC group $(P \leq 0.05)$ (Table 2). Faecal pH was lower in the DEA, DEC and DEG groups compared with the DC group; this suggests (a)

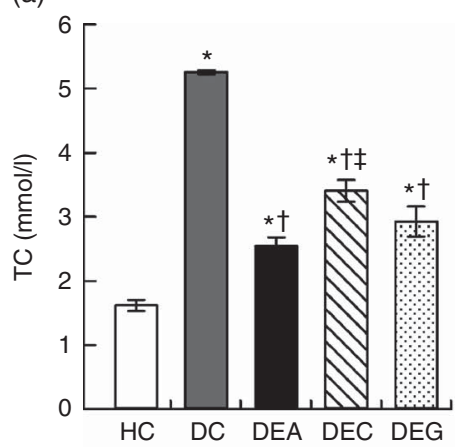

(b)

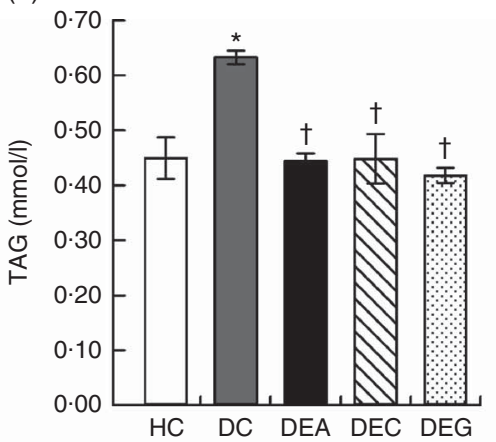

(c)

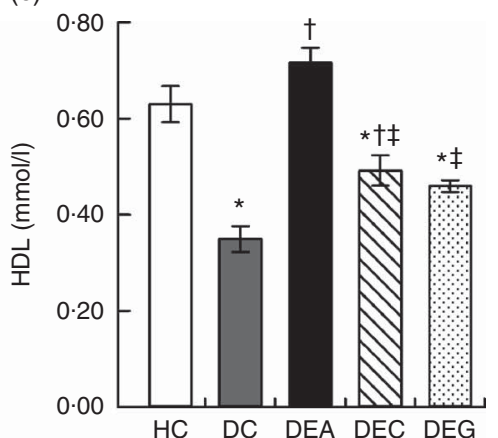

(d)

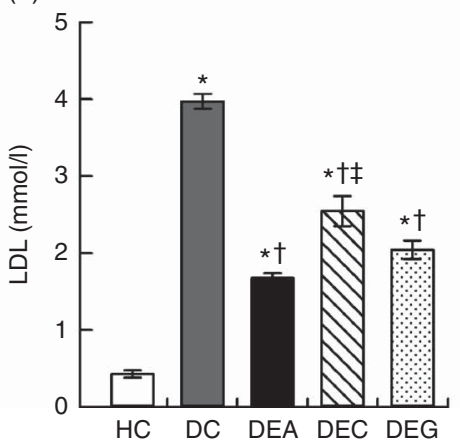

(e)

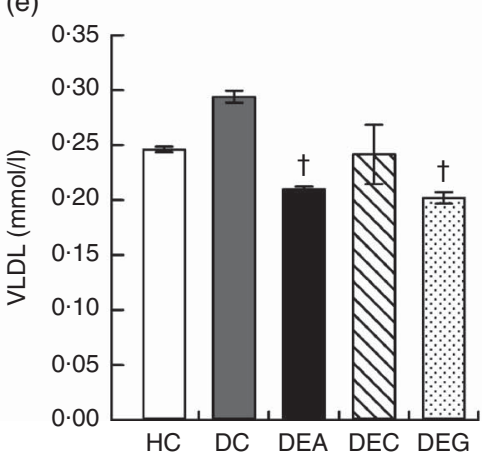

Fig. 1. Total cholesterol (a), TAG (b), HDL (c), LDL (d) and VLDL (e) of the healthy control animals (HC), non-treated dyslipidaemic control animals (DC) and dyslipidaemic animals that received acerola (DEA), cashew (DEC) or guava (DEG) industrial processing by-products. Values are means and standard deviations represented by vertical bars (one-way ANOVA, $P \leq 0.05$, Tukey's post hoc test). * Significant difference compared with the HC group, $\dagger$ significant difference compared with the DC group, $\ddagger$ significant difference compared with the DEA group. 
Table 1. Nutritional composition and phenolic compounds determined in freeze-dried acerola, cashew and guava industrial processing by-products

(Mean values and standard deviations)

\begin{tabular}{|c|c|c|c|c|c|c|}
\hline & \multicolumn{6}{|c|}{ By-product } \\
\hline & \multicolumn{2}{|c|}{ Acerola } & \multicolumn{2}{|c|}{ Cashew } & \multicolumn{2}{|c|}{ Guava } \\
\hline & Mean & SD & Mean & SD & Mean & SD \\
\hline \multicolumn{7}{|l|}{ Parameters } \\
\hline Moisture $(\mathrm{g} / 100 \mathrm{~g})$ & $3.30^{\mathrm{c}}$ & 0.10 & $6 \cdot 28^{\mathrm{b}}$ & 0.28 & $9.78^{a}$ & 0.17 \\
\hline Ash $(\mathrm{g} / 100 \mathrm{~g})$ & $3.08^{\mathrm{b}}$ & 0.20 & $2 \cdot 22^{\mathrm{c}}$ & $0 \cdot 10$ & $3.56^{\mathrm{a}}$ & 0.21 \\
\hline Protein $(\mathrm{g} / 100 \mathrm{~g})$ & $7 \cdot 18^{\mathrm{c}}$ & 0.10 & $9 \cdot 90^{\mathrm{b}}$ & 0.01 & $13 \cdot 78^{\mathrm{a}}$ & 0.19 \\
\hline Lipid $(\mathrm{g} / 100 \mathrm{~g})$ & $2.45^{\mathrm{b}}$ & 0.09 & $2 \cdot 15^{\mathrm{C}}$ & 0.00 & $9 \cdot 27^{\mathrm{a}}$ & 0.13 \\
\hline \multicolumn{7}{|l|}{ Simple sugars $(g / 100 g)$} \\
\hline Fructose & 9.64 & 0.02 & 18.96 & 0.02 & 8.66 & 0.00 \\
\hline Glucose & $9 \cdot 78$ & 0.02 & $17 \cdot 74$ & 0.01 & 15.96 & 0.01 \\
\hline Maltose & ND & - & 1.46 & 0.00 & ND & - \\
\hline \multicolumn{7}{|l|}{ Dietary fibre $(\mathrm{g} / 100 \mathrm{~g})$} \\
\hline Fructan & $1.40^{\mathrm{a}}$ & 0.01 & $1.06^{\mathrm{b}}$ & 0.02 & ND & - \\
\hline IDF & $34.35^{\mathrm{b}}$ & 0.29 & $27 \cdot 01^{\mathrm{c}}$ & 0.05 & $40 \cdot 62^{a}$ & 0.14 \\
\hline SDF & $14 \cdot 22^{\mathrm{a}}$ & 0.10 & $7.98^{\mathrm{b}}$ & 0.20 & $3.74^{\mathrm{C}}$ & 0.09 \\
\hline TDF & $48.57^{a}$ & 0.39 & $34.99^{\mathrm{C}}$ & 0.25 & $44 \cdot 36^{\mathrm{b}}$ & 0.23 \\
\hline IDF:SDF ratio & 2.42 & - & 3.39 & - & $10 \cdot 86$ & - \\
\hline Total energy value (kJ) & $497 \cdot 27$ & - & 568.48 & - & 703.04 & - \\
\hline Total energy value (kcal) & 118.85 & - & 135.87 & - & 168.03 & - \\
\hline \multicolumn{7}{|l|}{ Organic acids $(\mu \mathrm{mol} / \mathrm{g})$} \\
\hline Acetic & 43.63 & 0.00 & 12.99 & 0.00 & 9.99 & 0.00 \\
\hline Citric & ND & - & 4.48 & 0.00 & $5 \cdot 10$ & 0.02 \\
\hline Malic & 37.29 & 0.00 & 19.39 & 0.00 & 9.99 & 0.03 \\
\hline Tartaric & ND & - & 4.53 & 0.00 & ND & - \\
\hline \multicolumn{7}{|c|}{ Phenolic compounds (mg/100 g of dry weight) } \\
\hline \multicolumn{7}{|c|}{ Flavanol } \\
\hline Catechin & $125 \cdot 20^{\mathrm{a}}$ & 0.09 & $67 \cdot 00^{\mathrm{b}}$ & 0.03 & $4 \cdot 40^{c}$ & 0.08 \\
\hline \multicolumn{7}{|l|}{ Flavanone } \\
\hline Hesperetin & $9.00^{\mathrm{c}}$ & 0.01 & $12 \cdot 40^{\mathrm{a}}$ & 0.01 & $9 \cdot 60^{\mathrm{b}}$ & 0.01 \\
\hline Naringenin & $23.60^{\mathrm{b}}$ & 0.20 & $40 \cdot 60^{\mathrm{a}}$ & 0.11 & $18 \cdot 40^{\mathrm{C}}$ & 0.05 \\
\hline \multicolumn{7}{|l|}{ Flavone } \\
\hline Chrysin & $8.80^{\mathrm{a}}$ & 0.04 & $2 \cdot 00^{\mathrm{c}}$ & 0.02 & $2 \cdot 20^{\mathrm{b}}$ & 0.01 \\
\hline \multicolumn{7}{|l|}{ Flavonol } \\
\hline Kampferol & $42 \cdot 20^{a}$ & 0.01 & ND & - & ND & _- \\
\hline Myricetin & $94 \cdot 20^{\mathrm{a}}$ & 0.01 & $91.80^{\mathrm{b}}$ & 0.04 & $44 \cdot 60^{\mathrm{C}}$ & 0.01 \\
\hline Quercetin & $50 \cdot 80^{a}$ & 0.41 & $19 \cdot 80^{c}$ & 0.02 & $33.80^{\mathrm{b}}$ & 0.22 \\
\hline Rutin & $68 \cdot 60^{\mathrm{a}}$ & 0.05 & $67 \cdot 40^{\mathrm{b}}$ & 0.02 & $14 \cdot 40^{\mathrm{C}}$ & 0.06 \\
\hline Total flavonoids & 422.40 & - & 301.00 & - & 127.40 & - \\
\hline \multicolumn{7}{|l|}{ Hydroxybenzoic acids } \\
\hline 3,4-Dihydroxybenzoic acid & $97 \cdot 80^{\mathrm{c}}$ & 0.11 & $104 \cdot 80^{\mathrm{b}}$ & 0.27 & $143.40^{\mathrm{a}}$ & 0.30 \\
\hline 4-Hydroxybenzoic acid & $49.60^{\mathrm{a}}$ & 0.07 & ND & - & $21.40^{\mathrm{b}}$ & 0.08 \\
\hline 2,5-Dihydroxybenzoic acid & $737 \cdot 20^{\mathrm{a}}$ & 0.41 & ND & - & $89 \cdot 40^{\mathrm{b}}$ & 0.78 \\
\hline Ellagic acid & $49 \cdot 00^{\mathrm{a}}$ & 0.23 & $10 \cdot 40^{\mathrm{b}}$ & 0.20 & $1.00^{\mathrm{C}}$ & 0.01 \\
\hline Gallic acid & $36 \cdot 40^{\mathrm{a}}$ & 0.07 & $3 \cdot 80^{\mathrm{b}}$ & 0.08 & ND & - \\
\hline Syringic acid & $50.60^{\mathrm{a}}$ & 0.07 & $49 \cdot 80^{\mathrm{b}}$ & 0.02 & $5.00^{\mathrm{C}}$ & 0.02 \\
\hline Salicylic acid & $348.64^{\mathrm{a}}$ & 0.51 & $251.60^{\mathrm{C}}$ & 0.81 & $310 \cdot 60^{\mathrm{b}}$ & 0.89 \\
\hline Vanillic acid & $19 \cdot 40^{\mathrm{a}}$ & 0.09 & $4.40^{\mathrm{b}}$ & 0.04 & $2 \cdot 20^{\mathrm{C}}$ & 0.06 \\
\hline \multicolumn{7}{|l|}{ Hydroxycinnamic acids } \\
\hline Trans-cinnamic acid & $2 \cdot 20^{\mathrm{b}}$ & 0.01 & $2 \cdot 20^{\mathrm{b}}$ & 0.01 & $2 \cdot 60^{\mathrm{a}}$ & 0.02 \\
\hline Caffeic acid & $49 \cdot 40^{\mathrm{a}}$ & 0.05 & $20 \cdot 60^{\mathrm{b}}$ & 0.08 & $16 \cdot 20^{\mathrm{C}}$ & 0.07 \\
\hline$p$-Coumaric acid & $8 \cdot 20^{\mathrm{a}}$ & 0.06 & $0.60^{c}$ & 0.01 & $2.00^{\mathrm{b}}$ & 0.03 \\
\hline Felluric acid & $28 \cdot 00^{\mathrm{a}}$ & 0.02 & $10 \cdot 00^{\mathrm{b}}$ & 0.04 & ND & - \\
\hline Synapic acid & ND & - & 43.00 & - & $18 \cdot 80$ & _- \\
\hline Total non-flavonoids & 1476.44 & - & $501 \cdot 20$ & - & $612 \cdot 60$ & - \\
\hline Total phenolic compounds & 1898.84 & - & $802 \cdot 20$ & _- & 740.00 & - \\
\hline
\end{tabular}

increased DF fermentation and organic acid production by colonic microbiota, causing faecal acidification in rats fed on the tested fruit by-products ${ }^{(51,52)}$. Consumption of a diet rich in resistant starch or fructo-oligossacharides has also shown an ability to decrease faecal $\mathrm{pH}$ in rats ${ }^{(53,54)}$.
Faecal moisture was higher in the DC group than in the HC group $(P \leq 0 \cdot 05)$. The DEA group presented increased faecal moisture compared with the HC group $(P \leq 0.05)$ (Table 2$)$, which could be related to better water retention in the colon caused by a balanced DF intake. Increased faecal moisture was 
Table 2. Faecal moisture $(\mathrm{g} / 100 \mathrm{~g}), \mathrm{pH}$ and organic acids $(\mu \mathrm{mol} / \mathrm{g})$ in healthy control animals, non-treated dyslipidaemic control animals and dyslipidaemic animals that received acerola, cashew or guava industrial processing fruit by-products

(Mean values and standard deviations)

\begin{tabular}{|c|c|c|c|c|c|c|c|c|c|c|}
\hline \multirow[b]{3}{*}{ Parameters } & \multicolumn{10}{|c|}{ Groups } \\
\hline & \multicolumn{2}{|c|}{$\mathrm{HC}$} & \multicolumn{2}{|c|}{ DC } & \multicolumn{2}{|c|}{ DEA } & \multicolumn{2}{|c|}{ DEC } & \multicolumn{2}{|c|}{ DEG } \\
\hline & Mean & SD & Mean & SD & Mean & SD & Mean & SD & Mean & SD \\
\hline Moisture & $40 \cdot 44^{c}$ & 0.40 & $53 \cdot 20^{\mathrm{a}}$ & 0.43 & $42 \cdot 64^{\mathrm{b}}$ & 0.23 & $41 \cdot 55^{\mathrm{b}, \mathrm{c}}$ & 0.42 & $35 \cdot 98^{d}$ & \\
\hline $\mathrm{pH}$ & $7.02^{\mathrm{e}}$ & 0.01 & $8 \cdot 62^{\mathrm{a}}$ & 0.01 & $7 \cdot 89^{\mathrm{b}}$ & 0.02 & $7 \cdot 39^{d}$ & 0.05 & $7 \cdot 61^{c}$ & 0.06 \\
\hline Acetic acid & $59.67^{\mathrm{a}}$ & 2.39 & $27 \cdot 87^{c}$ & 0.85 & $45 \cdot 44^{\mathrm{b}}$ & 0.80 & $27 \cdot 17^{c}$ & 0.45 & $29.01^{c}$ & 0.80 \\
\hline Formic acid & ND & - & ND & - & 20.92 & 0.09 & ND & - & ND & - \\
\hline Total SCFA & $59.67^{b}$ & $1 \cdot 19$ & $27.87^{\mathrm{c}, \mathrm{d}}$ & 0.43 & $66 \cdot 36^{\mathrm{a}}$ & 0.45 & $27 \cdot 17^{d}$ & 0.22 & $29.01^{\mathrm{C}}$ & 0.40 \\
\hline Citric acid & $1 \cdot 14^{\mathrm{c}}$ & 0.16 & $8 \cdot 24^{a}$ & 1.46 & $3 \cdot 80^{\mathrm{b}}$ & 0.20 & $7 \cdot 64^{a}$ & 0.02 & $2 \cdot 47^{\mathrm{b}, \mathrm{c}}$ & 0.42 \\
\hline Lactic acid & $55 \cdot 92^{\mathrm{a}}$ & 1.88 & $27 \cdot 72^{\mathrm{b}}$ & 1.60 & $8 \cdot 16^{c}$ & 0.67 & $47.59^{a}$ & 8.77 & $11 \cdot 17^{\mathrm{C}}$ & 0.86 \\
\hline Malic acid & $0.51^{\mathrm{c}}$ & 0.02 & $1.66^{\mathrm{c}}$ & 1.20 & $47 \cdot 72^{\mathrm{a}}$ & 0.94 & $7 \cdot 71^{\mathrm{b}}$ & 0.28 & $0.56^{\mathrm{c}}$ & 0.08 \\
\hline Total organic acids & $117 \cdot 24^{\mathrm{b}}$ & $2 \cdot 31$ & $65.49^{d}$ & 2.56 & $126 \cdot 04^{\mathrm{a}}$ & 1.36 & $90 \cdot 11^{c}$ & 4.76 & $43 \cdot 21^{e}$ & 1.08 \\
\hline
\end{tabular}

$\mathrm{HC}$, healthy control; DC, non-treated dyslipidaemic control; DEA, dyslipidaemic group supplemented with acerola by-product; DEC, dyslipidaemic group supplemented with cashew by-product; DEG, dyslipidaemic group supplemented with guava by-product; ND, not detected.

$\mathrm{a}, \mathrm{b}, \mathrm{c}, \mathrm{d}, \mathrm{e}$ Mean values in the same row with unlike superscript letters were significantly different between the mean of the each group (one-way ANOVA, $P \leq 0 \cdot 05$, Tukey's post hoc test).

not observed in the DEG group. The guava by-products showed the highest IDF content and IDF/SDF ratio. In addition, the guava and cashew by-products presented high amounts of tannins ${ }^{(16,55)}$, which have been shown to have antisecretory activity, inducing decreased intraluminal fluid, increased water reabsorption, reduced intestinal motility and, consequently, reduced moisture in faeces ${ }^{(56)}$.

Diets presenting IDF/SDF ratio in the range of $1 \cdot 0-2 \cdot 3$ typically present better capability of modulating physiological processes ${ }^{(10)}$. Supplementation with acerola by-products (IDF: SDF ratio: 2.42) should produce the best DF fractions balance, compared with cashew and guava by-products. Consumption of a diet containing an adequate DF balance might benefit intestinal functions by increasing faecal volume, as a result of increased water absorption ${ }^{(57)}$, facilitating faecal excretion ${ }^{(54)}$.

Production of organic acids, particularly SCFA, is directly related to selective fermentation of potentially prebiotic components by colonic bacteria ${ }^{(58)}$. Although SCFA can be used as energy sources by the host, they can also act as energy consumption and metabolism regulators ${ }^{(59)}$. SCFA can improve blood lipid levels by suppressing hepatic lipogenesis and increasing oxidative metabolism ${ }^{(26)}$. The highest contents of acetic acid were found in faeces of the HC group, followed by the DEA group $(P \leq 0 \cdot 05)$. Formic acid was found only in the faeces of the DEA group. Highest total SCFA contents were found in the faeces of the DEA group $(P \leq 0.05)$. Lactic acid was the organic acid found in highest amounts in the faeces of the HC, DC, DEC and DEG groups; malic acid was the organic acid found in the highest amount in the faeces of the DEA group $(P \leq 0 \cdot 05)$ (Table 2).

Considering that the acerola by-product exhibited high SDF content, the increased acetic acid content observed in the faeces of the DEA group could be related to increased colonic SDF fermentation ${ }^{(18)}$. Moderate amounts of acetic acid detected in the acerola by-product (Table 1) could be related to the detection of increased amounts of formic acid in faeces of the DEA group. Formic acid is used as substrate for acetic acid production by acetogenic bacteria via the Wood-Ljungdahl pathway $^{(60)}$. In the present study, butyric and propionic acids were not detected in the animals' faeces regardless of the consumption of acerola, cashew or guava by-products. One possible reason for this is that $95 \%$ of SCFA produced in large intestine is quickly absorbed by colonocytes, whereas only the remaining $5 \%$ is expelled in faeces ${ }^{(24)}$.

The DC group exhibited higher faecal counts of Enterobacteriaceae (Fig. 2(b)) and lower counts of Bifidobacterium spp. and Lactobacillus spp. (Fig. 2(a) and (c)) than the HC, DEA, DEC and DEG groups $(P \leq 0.05)$. The DEA group showed higher faecal counts of Bifidobacterium spp. and Lactobacillus spp. than the DC group $(P \leq 0.05)$ and similar to HC group $(P>0.05)$, suggesting that the DF and fructans present in acerola by-products (Table 1) may stimulate the increase in populations of these beneficial microorganisms in the intestine ${ }^{(35,61)}$. Phenolic compounds present in acerola processing by-products (Table 1) might also contribute to these stimulatory effects, as up to $90 \%$ of plant phenolics may reach the colon where they are used as substrates for production of small phenolic acids by intestinal microbiota ${ }^{(21)}$. Small phenolic acids affect intestinal microbial composition and are used as substrates for organic acid production by colonic bacteria ${ }^{(21,37)}$. Bifidobacteria and lactobacilli can normalise fat metabolism through TAG synthesis and mineral absorption, which is also associated with a reduced incidence of colon cancer ${ }^{(62)}$. Furthermore, DF can bind to phenolic compounds and, consequently, reduce their absorption in the small intestine. This permits a high proportion of ingested phenolic compounds to reach the large intestine to be fermented, contributing to the growth of beneficial bacterial species (e.g. Bifidobacterium and Lactobacillus) and inhibiting the growth of pathogenic bacteria (e.g. Clostridium perfringens and Enterobacteriaceae) ${ }^{(63)}$.

The DEA and DEG groups presented lower faecal counts of Enterobacteriaceae compared with the DC group $(P \leq 0.05)$. Increased counts of Bifidobacterium spp. and Lactobacillus spp. and reduced counts of $C$. perfringens was previously verified in the caecum contents of hamsters fed a diet supplemented with pineapple peel (rich in IDF). These results were 
(a)

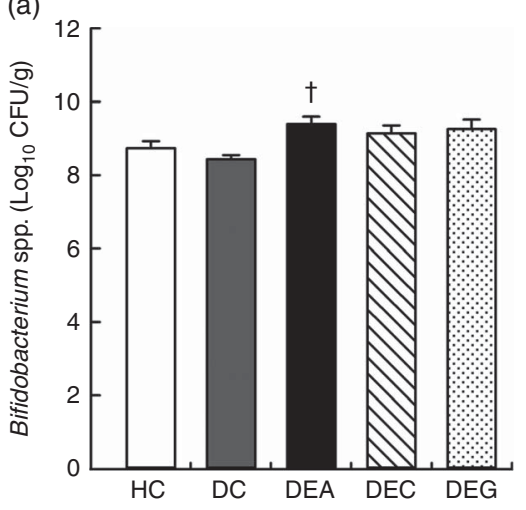

(b)

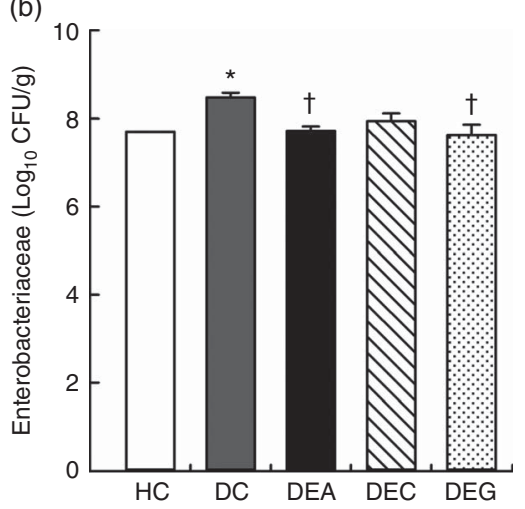

(c)

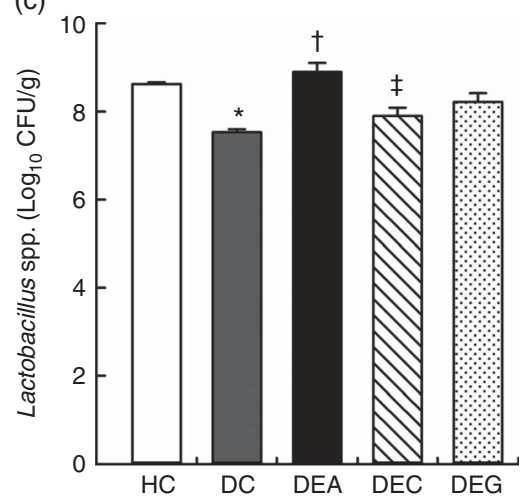

Fig. 2. Viable cell count of Bifidobacterium spp. (a), Enterobacteriaceae (b) and Lactobacillus spp. (c), in faeces of the healthy control animals (HC), non-treated dyslipidaemic control animals (DC) and dyslipidaemic animals that received acerola (DEA), cashew (DEC) or guava (DEG) industrial processing by-products. Values are means and standard deviations represented by vertical bars (one-way ANOVA, $P \leq 0.05$, Tukey's post hoc test). CFU, colony-forming units. ${ }^{\star}$ Significant difference compared with the $\mathrm{HC}$ group, $†$ significant difference compared with the DC group, $\ddagger$ significant difference compared with the DEA group.

(a)

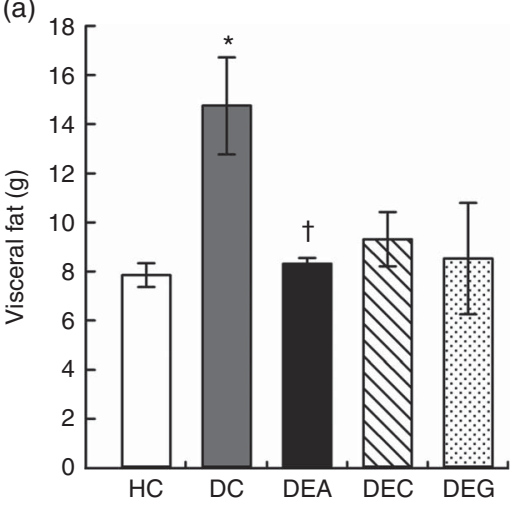

(b)

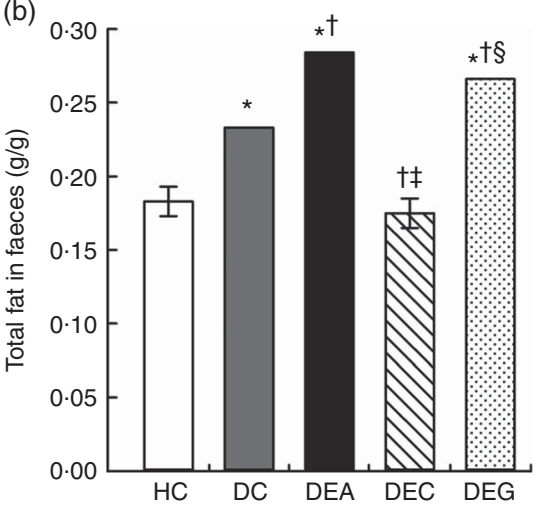

(c)

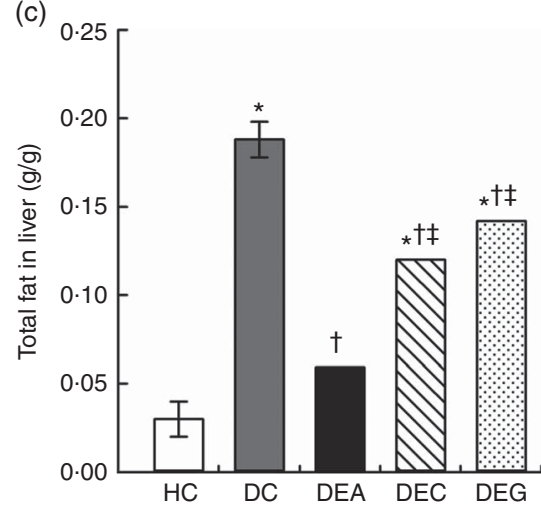

Fig. 3. Visceral fat (a), total fat in the faeces (b) and liver (c) of the healthy control animals (HC), non-treated dyslipidaemic control animals (DC) and dyslipidaemic experimental animals that received acerola (DEA), cashew (DEC) or guava (DEG) industrial processing by-products. Values are means and standard deviations represented by vertical bars (one-way ANOVA, $P \leq 0.05$, Tukey's post hoc test). * Significant difference compared with the HC group, $\dagger$ significant difference compared with the DC group, $\ddagger$ significant difference compared with the DEA group, § significant difference compared with the DEC group.

related to increased production of SCFA and antimicrobial substances in hamsters' intestine ${ }^{(35)}$. Decreased luminal $\mathrm{pH}$ values, as observed in the DEA and DEG groups, were associated with changes in intestinal microbiota composition, hampering the growth of $\mathrm{pH}$-sensitive pathogenic bacteria, such as Enterobacteriaceae ${ }^{(24)}$.

\section{Effects on visceral fat, total fat in faeces and liver}

The visceral fat amount was higher in the DC group than in the DEA and HC groups $(P \leq 0.05)$, indicating that supplementation with acerola by-products decreased the effects of excessive fat intake on visceral adipose tissue (Fig. 3(a)).

Fat amount in faeces was higher in the DEA and DEG group compared with the HC, DC and DEC groups $(P \leq 0.05)$ (Fig. 3(b)). High total fibre content in acerola and guava by-products may have favoured a decrease in fat absorption in the intestine ${ }^{(44,64)}$ and, consequently, an increase in fat excretion in the faeces. DF and phenolic contents in bread containing an oven-dried or lyophilised extract of red grape processing by-products has been associated with increased fat excretion in faeces and less accumulation of visceral fat in hypercholesterolaemic rats ${ }^{(65)}$. Fat excretion in faeces may have influenced the higher weight losses in the DEA and DEG groups because energy loss through faeces impacts directly on the amount of metabolisable energy in a diet ${ }^{(66)}$.

The DC group exhibited higher amounts of liver fat than the HC, DEA, DEC and DEG groups $(P \leq 0 \cdot 05)$ (Fig. 3(c)). High-fat diet consumption can lead to the development of NAFLD, such as hepatic steatosis, which is characterised by fat accumulation in more than $5 \%$ of liver cells ${ }^{(67)}$. In hepatic steatosis, there is increased formation of reactive oxygen species that damage hepatic tissue and cause mitochondrial dysfunction, reduction of $\beta$-oxidation and elevation of TAG production, which could justify the elevation of serum TAG levels in the DC group, as previously discussed ${ }^{(68)}$.

The lowest amounts of liver fat were found in the DEA group $(P \leq 0.05)$, indicating a hepatoprotective effect from supplementation with the acerola by-products. The hepatoprotective effects induced by the acerola by-products may also be related 
to the majority phenolics (catechin, myricetin, quercetin, rutin, 2,5-dihydroxybenzoic acid, syringic acid and salicylic acid) found in this material (Table 1). These compounds induce reduced liver fat deposition by decreasing fatty acid synthesis and lipogenic enzyme activity, as well as promoting cellular $\beta$-oxidation and lipophagy ${ }^{(3,69)}$. In addition, a lower amount of liver fat in the DEA group could indicate decreased activity of the lipogenic enzymes, such as lipoprotein lipase, involved in metabolism and transport of TAG-rich lipoproteins (chylomicrons and VLDL) ${ }^{(70)}$.

\section{Effects on histopathological characteristics of intestine and liver}

Histopathological examination of H\&E-stained colon samples revealed that consumption of dyslipidaemic diet caused epithelial destruction (Fig. 4(b), $\mathbf{\Delta}$ ) with the loss of organ integrity and epithelial conservation $(\longleftarrow)$. Colon samples stained with PAS showed loss of organ integrity, as evidenced by reduced goblet cell number (Fig. 5(b), $\mathbf{\Delta}$ ) in the DC group colonic mucosa. The HC group exhibited a normal colonic epithelial structure (Fig. 4(a) and 5(a)), and colon in the DEA, DEC and DEG groups (Fig. 4(c)-(e) and Fig. 5(c)-(e)) did not show morphological changes induced by the dyslipidaemic diet. The DEA, DEC and DEG groups showed maintenance of integrity of crypts, goblet cells and epithelial cells, indicating improved colon health. Goblet cells produce intestinal mucus and are among the most abundant cell types in colonic mucosa, exerting an important role in colon health ${ }^{(71)}$. DF and fructan amounts in acerola, cashew and guava by-products may have protected colon tissue from damage caused by a dyslipidaemic diet, as previously observed in rats fed a diet added with yacon root (rich in fructooligosaccharide) or fed a diet containing resistant $\operatorname{starch}^{(53)}$. The production of SCFA from the intestinal microbial fermentation of
DF and phenolic compounds contained in acerola, cashew and guava by-products may have positively affected intestinal health, as SCFA are the main source of energy for the colonocytes ${ }^{(26)}$.

The liver architecture of the HC group was normal (Fig. 6(a)). However, the dyslipidaemic diet led to the fat accumulation in hepatocytes, and both hepatic steatosis (arrowhead) and blood stasis (black arrow) were observed in the DC group (Fig. 6(b)). The DEC (Fig. 6(d)) and DEG groups (Fig. 6(e)) exhibited reduction in steatosis compared with the DC group. The DEA group presented minor degenerative changes in the liver (Fig. 6(c)) compared with the DC, DEC and DEG groups. Previous studies on histopathological examinations of liver samples have found increased fat deposits in the livers of rodents fed a high-fat diet. These changes were reduced, however, after the animals received a high-fat diet with dehydrated Rosa laevigata Michx fruit, which contains a high amount of flavonoids ${ }^{(72)}$, as well as with dried oranges, strawberries and pomegranates ${ }^{(44)}$. These hepatic protective effects were related to the existence of potential synergism among phenolic compounds present in tested materials. Fruit rich in phenolic compounds have also presented a protective effect against increased hepatic fat deposits in animals fed a high-fat diet ${ }^{(73-75)}$. Phenolic compounds can minimise hepatic steatosis by regulating the activity of the antioxidant enzyme paraoxonase, which protects against the development of hypercholesterolaemia and atherogenesis ${ }^{(74)}$, as well as by decreasing hepatic lipogenesis through the activation of the hepatic cyclic AMP (30,50-monophosphate) (cAMP)/protein kinase A/cAMP-responsive element binding protein pathway ${ }^{(26)}$.

\section{Conclusions}

In general, supplementation with acerola, cashew or guava industrial processing by-products reduced weight gain, faecal

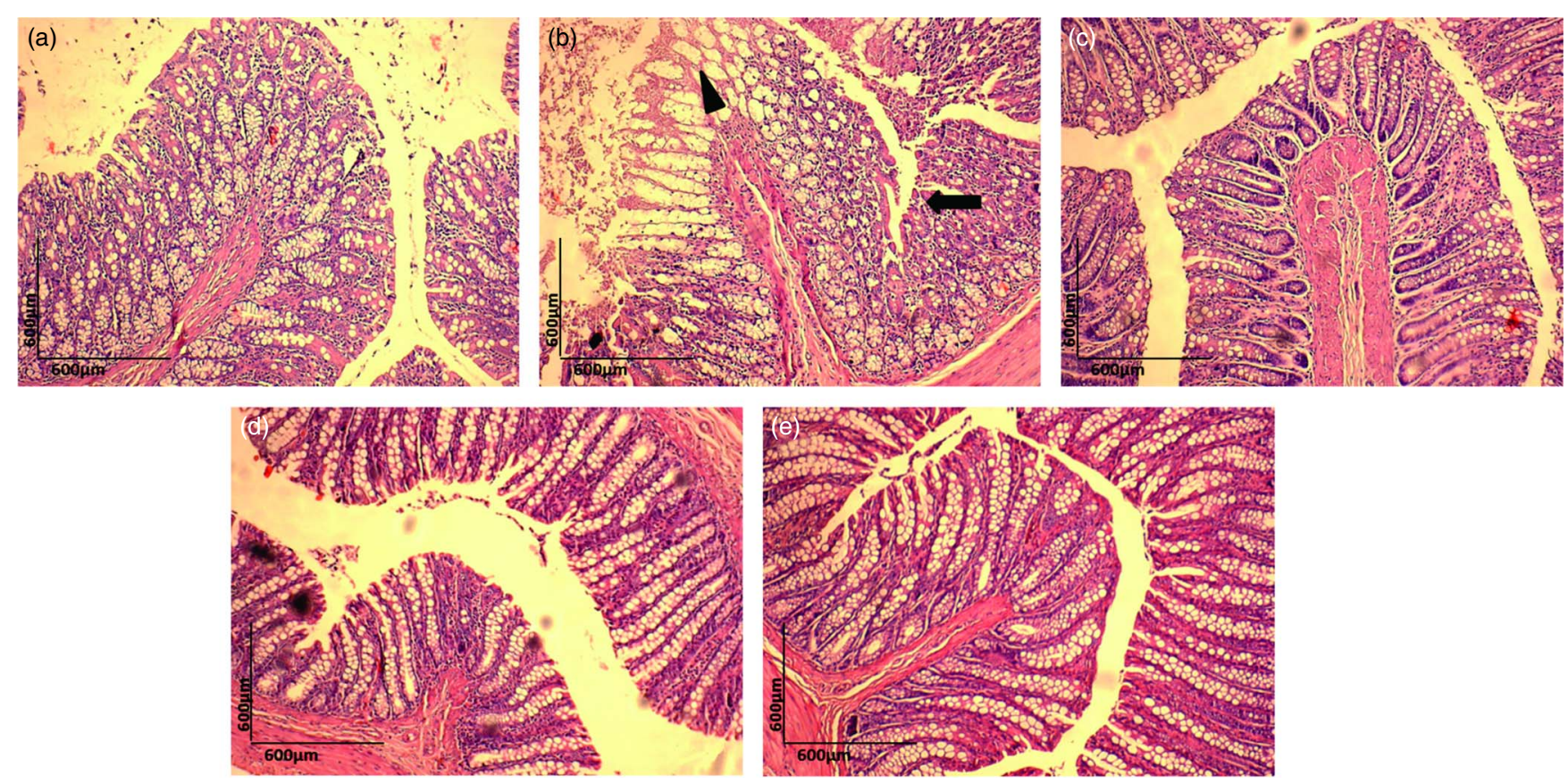

Fig. 4. Haematoxylin-eosin (H\&E) staining (10x) for histopathological examination of the colon in the healthy control animals (a), non-treated dyslipidaemic control animals (b) and dyslipidaemic animals that received acerola (c), cashew (d) or guava (e) industrial processing fruit by-products. 


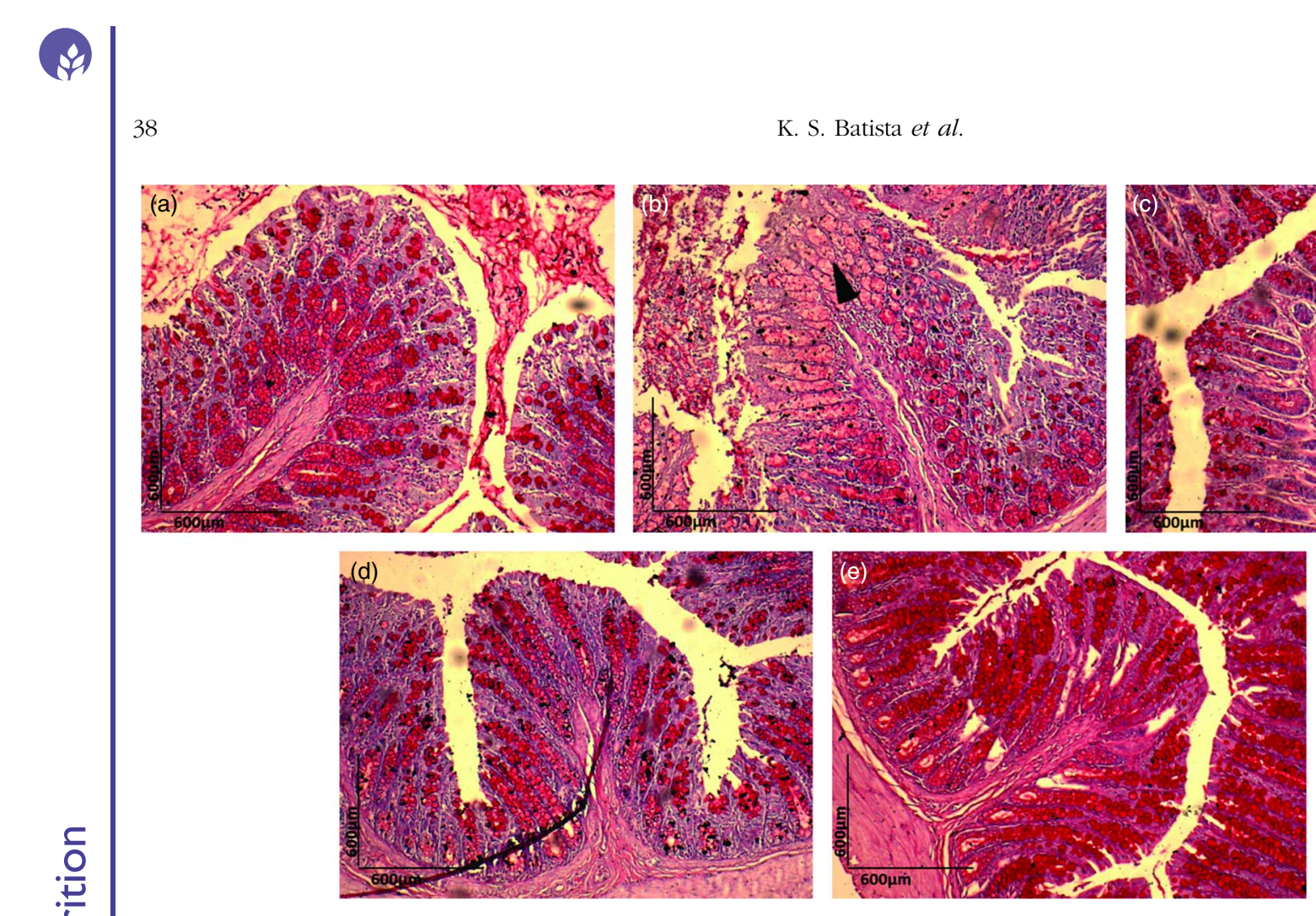

Fig. 5. Periodic acid-Schiff (PAS) staining (10x) for histopathological examination of the colon in the healthy control animals (a), non-treated dyslipideamic control animals (b) and dyslipidaemic animals that received acerola (c), cashew (d) or guava (e) industrial processing fruit by-products.
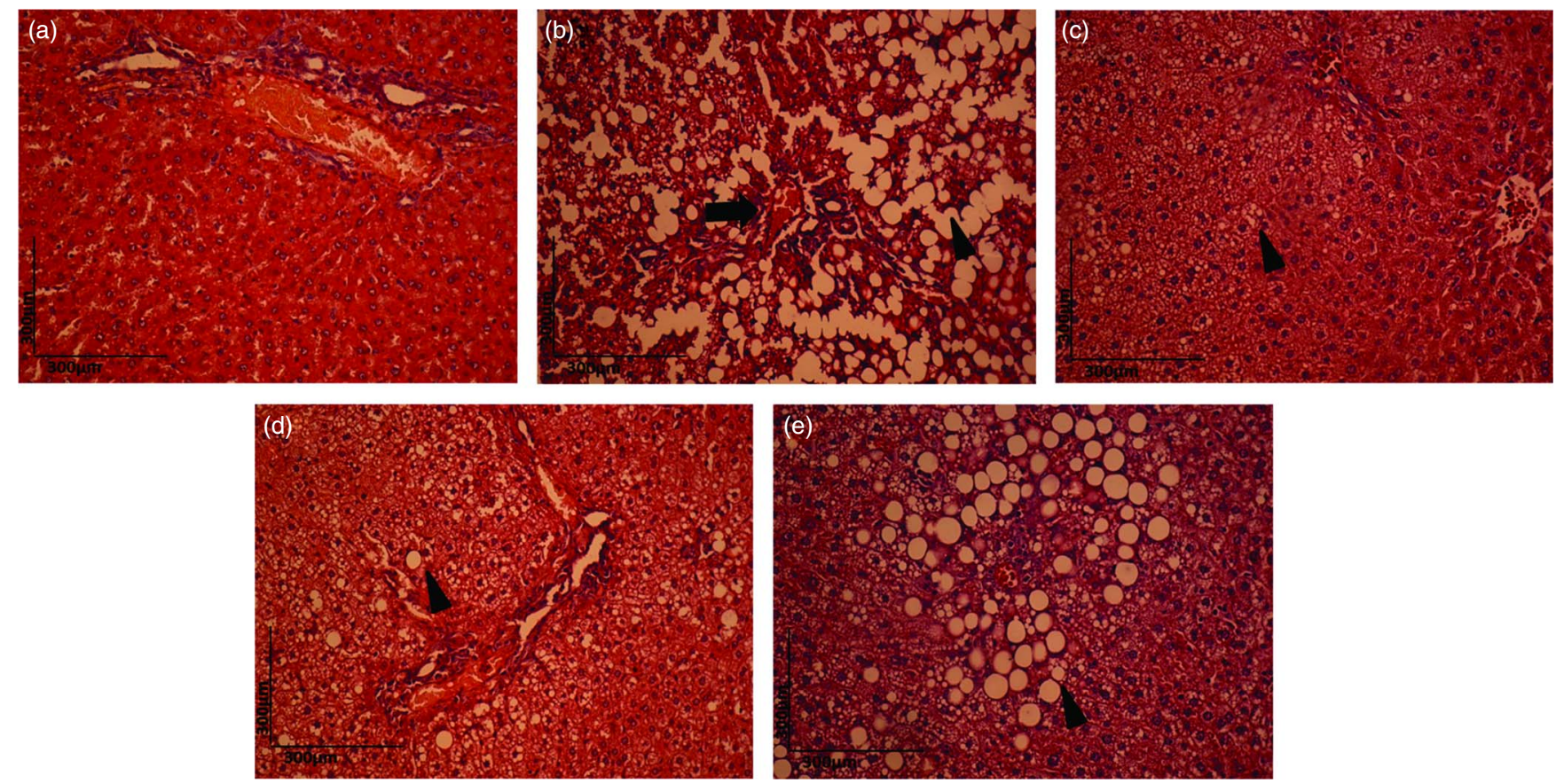

Fig. 6. Haematoxylin-eosin (H\&E) staining (10x) for histopathological examination of the liver in the healthy control animals (a), non-treated dyslipidaemic control animals (b) and dyslipidaemic animals that received acerola (c), cashew (d) or guava (e) industrial processing fruit by-products.

$\mathrm{pH}$, liver fat accumulation, preserved colonic epithelial integrity and liver cell structure in dyslipidaemic female Wistar rats. Acerola and cashew processing by-products increased faecal moisture, and acerola and guava by-products increased fat excretion in faeces. The consumption of acerola processing by-products had the greatest effects on the monitored parameters. Its consumption of acerola by-products by dyslipidaemic female rats increased faecal counts of beneficial bacteria belonging to the Bifidobacterium and Lactobacillus genera, in addition to inducing higher organic acid production in the intestine, attenuating visceral fat accumulation and lipid profile changes. Protective effects of acerola by-products may be associated with its high amounts of phenolic compounds and other bioactive compounds and DF balance. These results 
encourage considering the safe use of acerola, cashew and guava by-products to protect the harmful effects caused by a dyslipidaemic diet on intestinal health and lipid metabolism. This use could be either as dietary supplements or as ingredients used in food products.

\section{Acknowledgements}

The authors thank the Coordination for the Improvement of Higher Education Personnel (Coordenação de Aperfeiçoamento de Pessoal de Nível Superior; CAPES) for a scholarship to K. S. B. and the National Council for Scientific and Technological Development (Conselho Nacional de Desenvolvimento Científico e Tecnológico; CNPq) (grant no. 476302/2013-7) for financial support.

The authors thank Sidney Pratt for the revision of English.

K. S. B., A. S. S., E. L. d. S. and J. d. S. A. conceived the study, performed literature searches, wrote the manuscript and reviewed the final draft. M. d. S. L., B. R. L. d. A. M. and A. M. T. d. M. performed the characterisation analyses of fruit by-products and the statistical analysis of these results. K. S. B., A. F. A., L. A. d. S., P. P. L., J. A. d. S. G., L. T. T. and M. L. d. C. performed the biological assay and literature searches. K. S. B., M. L. d. C. and L. T. T. performed statistical analyses of the data and wrote the manuscript.

The authors declare that there are no conflicts of interest.

\section{Supplementary material}

For supplementary material/s referred to in this article, please visit https://doi.org/10.1017/S0007114517003282

\section{References}

1. Xavier HT, Izar MC, Faria Neto JR, et al. (2013) V Brazilian guidelines on dyslipidemias and prevention of atherosclerosis. Arq Bras Cardiol 101, 1-22.

2. Kotronen A \& Yki-Jarvinen H (2008) Fatty liver: a novel component of the metabolic syndrome. Arterioscler Thromb Vasc Biol 28, 27-38.

3. Parafati M, Lascala A, Morittu VM, et al. (2015) Bergamot polyphenol fraction prevents nonalcoholic fatty liver disease via stimulation of lipophagy in cafeteria diet-induced rat model of metabolic syndrome. I Nutr Biochem 26, 938-948.

4. Gaggini M, Morelli M, Buzzigoli E, et al. (2013) Non-alcoholic fatty liver disease (NAFLD) and its connection with insulin resistance, dyslipidemia, atherosclerosis and coronary heart disease. Nutrients 5, 1544-1560.

5. Alheiros-Lira MC, Jurema-Santos GC, da-Silva HT, et al. (2017) Effects of high-fat diet on somatic growth, metabolic parameters and function of peritoneal macrophages of young rats submitted to a maternal low-protein diet. BrJ Nutr 117, 796-803.

6. Anderson TJ, Gregoire J, Hegele RA, et al. (2013) 2012 update of the Canadian Cardiovascular Society guidelines for the diagnosis and treatment of dyslipidemia for the prevention of cardiovascular disease in the adult. Can J Cardiol 29, 151-167.

7. Grundy SM, Arai H, Barter P, et al. (2014) An International Atherosclerosis Society Position Paper: global recommendations for the management of dyslipidemia - full report. J Clin Lipidol 8, 29-60.
8. Raasmaja A, Lecklin A, Li XM, et al. (2013) A water-alcohol extract of Citrus grandis whole fruits has beneficial metabolic effects in the obese Zucker rats fed with high fat/high cholesterol diet. Food Chem 138, 1392-1399.

9. Yoo JH, Liu Y \& Kim HS (2016) Hawthorn fruit extract elevates expression of $\mathrm{Nrf} 2 / \mathrm{HO}-1$ and improves lipid profiles in ovariectomized rats. Nutrients $\mathbf{8}, 283$.

10. Martinez R, Torres P, Meneses MA, et al. (2012) Chemical, technological and in vitro antioxidant properties of mango, guava, pineapple and passion fruit dietary fibre concentrate. Food Chem 135, 1520-1526.

11. Mezadri T, Villaño D, Fernández-Pachón MS, et al. (2008) Antioxidant compounds and antioxidant activity in acerola (Malpighia emarginata DC.) fruits and derivatives. I Food Compost Anal 21, 282-290.

12. Santos RP, Santiago AAX, Gadelha CAA, et al. (2007) Production and characterization of the cashew (Anacardium occidentale L.) peduncle bagasse ashes. J Food Eng 79, 1432-1437.

13. Ayala-Zavala JF, Vega-Vega V, Rosas-Domínguez C, et al. (2011) Agro-industrial potential of exotic fruit byproducts as a source of food additives. Food Res Int 44, 1866-1874.

14. Marques TR, Corrêa AD, Lino JBdR, et al. (2013) Chemical constituents and technological functional properties of acerola (Malpighia emarginata DC.) waste flour. Food Sci Technol (Campinas) 33, 526-531.

15. Guedes-Oliveira JM, Salgado RL, Costa-Lima BRC, et al. (2016) Washed cashew apple fiber (Anacardium occidentale L.) as fat replacer in chicken patties. $L W T$ - Food Sci Technol 71, 268-273.

16. Amaya-Cruz DM, Rodríguez-González S, Pérez-Ramírez IF, et al. (2015) Juice by-products as a source of dietary fibre and antioxidants and their effect on hepatic steatosis. I Funct Foods 17, 93-102.

17. Ribeiro da Silva LM, Teixeira de Figueiredo EA, Silva Ricardo NM, et al. (2014) Quantification of bioactive compounds in pulps and by-products of tropical fruits from Brazil. Food Chem 143, 398-404.

18. da Silva JK, Cazarin CBB, Bogusz Junior S, et al. (2014) Passion fruit (Passiflora edulis) peel increases colonic production of short-chain fatty acids in Wistar rats. LWT - Food Sci Technol 59, 1252-1257.

19. Slavin J (2013) Fiber and prebiotics: mechanisms and health benefits. Nutrients 5, 1417-1435.

20. Barczynska R, Slizewska K, Litwin M, et al. (2015) The effect of dietary fibre preparations from potato starch on the growth and activity of bacterial strains belonging to the phyla Firmicutes, Bacteroidetes, and Actinobacteria. J Funct Foods 19, 661-668.

21. Parkar SG, Trower TM \& Stevenson DE (2013) Fecal microbial metabolism of polyphenols and its effects on human gut microbiota. Anaerobe 23, 12-19.

22. Alqurashi RM, Alarifi SN, Walton GE, et al. (2017) In vitro approaches to assess the effects of acai (Euterpe oleracea) digestion on polyphenol availability and the subsequent impact on the faecal microbiota. Food Chem 234, 190-198.

23. Mosele JI, Macia A, Romero MP, et al. (2016) Stability and metabolism of Arbutus unedo bioactive compounds (phenolics and antioxidants) under in vitro digestion and colonic fermentation. Food Chem 201, 120-130.

24. den Besten G, van Eunen K, Groen AK, et al. (2013) The role of short-chain fatty acids in the interplay between diet, gut microbiota, and host energy metabolism. J Lipid Res 54, $2325-2340$

25. Kaczmarczyk MM, Miller MJ \& Freund GG (2012) The health benefits of dietary fiber: beyond the usual suspects of type 2 diabetes mellitus, cardiovascular disease and colon cancer. Metabolism 61, 1058-1066. 
26. Wang Z, Koonen D, Hofker M, et al. (2016) Gut microbiome and lipid metabolism: from associations to mechanisms. Curr Opin Lipidol 27, 216-224.

27. Association of Official Analytical Chemists (AOAC) (2011) Official Methods of Analysis of AOAC International, 18th ed. Gaitheresburg, MD: AOAC International.

28. Prosky L, Asp N, Schweizer T, et al. (1992) Determination of insoluble and soluble dietary fibers in foods and food products: collaborative study. J AOAC Int 75, 360-367.

29. Duarte FN, Rodrigues JB, da Costa Lima M, et al. (2017) Potential prebiotic properties of cashew apple (Anacardium occidentale L.) agro-industrial byproduct on Lactobacillus species. J Sci Food Agric 97, 3712-3719.

30. Reeves PG, Nielsen FH \& Fahey GC Jr (1993) AIN-93 purified diets for laboratory rodents: final report of the American Institute of Nutrition ad hoc writing committee on the reformulation of the AIN-76A rodent diet. J Nutr 123, 1939-1951.

31. Bouderbala S, Lamri-Senhadji M, Prost J, et al. (2008) Changes in antioxidant defense status in hypercholesterolemic rats treated with Ajuga iva. Phytomedicine 15, 453-461.

32. Lakshmi BV, Sudhakar M \& Aparna M (2013) Protective potential of Black grapes against lead induced oxidative stress in rats. Environ Toxicol Pharmacol 35, 361-368.

33. Friedewald WT, Levy RI \& Fredrickson DS (1972) Estimation of the concentration of low-density lipoprotein cholesterol in plasma, without use of the preparative ultracentrifuge. Clin Chem 18, 499-502.

34. Asvarujanon P, Ishizuka S \& Hara H (2005) Promotive effects of non-digestible disaccharides on rat mineral absorption depend on the type of saccharide. Nutrition 21, 1025-1035.

35. Huang YL, Tsai YH \& Chow CJ (2014) Water-insoluble fiberrich fraction from pineapple peel improves intestinal function in hamsters: evidence from cecal and fecal indicators. Nutr Res 34, 346-354

36. Miles AA, Misra SS \& Irwin JO (1938) The estimation of the bactericidal power of the blood. Epidemiol Infect 38, 732-749.

37. da Silva JK, Cazarin CBB, Colomeu TC, et al. (2013) Antioxidant activity of aqueous extract of passion fruit (Passiflora edulis) leaves: in vitro and in vivo study. Food Res Int 53, 882-890.

38. Folch J, Lees M \& Sloane Stanley GH (1957) A simple method for the isolation and purification of total lipides from animal tissues. J Biol Chem 226, 497-509.

39. Ball S \& Lloyd L (2011) Agilent Hi-Plex columns for carbohydrates, alcohols, and acids. In Analysis of Carbohydrates, Alcohols, and Organic Acids by Ion-Exchange Chromatography, pp. 1-98 [Agilent Technologies Inc., editor]. Santa Clara, CA: Agilent Technologies Inc.

40. Duca FA, Zhong L \& Covasa M (2013) Reduced CCK signaling in obese-prone rats fed a high fat diet. Horm Behav 64, 812-817.

41. Perry B \& Wang Y (2012) Appetite regulation and weight control: the role of gut hormones. Nutr Diabetes $\mathbf{2}$, e26.

42. Parnell JA \& Reimer RA (2012) Prebiotic fibres dosedependently increase satiety hormones and alter Bacteroidetes and Firmicutes in lean and obese JCR:LA-cp rats. $\mathrm{Br} J$ Nutr 107, 601-613.

43. Brownlee IA, Chater PI, Pearson JP, et al. (2017) Dietary fibre and weight loss: where are we now? Food Hydrocoll $\mathbf{6 8}$, 186-191.

44. Esmael OA, Sonbul SN, Kumosani TA, et al. (2015) Hypolipidemic effect of fruit fibers in rats fed with high dietary fat. Toxicol Ind Health 31, 281-288.

45. Dias FM, Leffa DD, Daumann F, et al. (2014) Acerola (Malpighia emarginata DC.) juice intake protects against alterations to proteins involved in inflammatory. Lipids Health Dis 13, 24.
46. Kwok C-Y, Li C, Cheng H-L, et al. (2013) Cholesterol lowering and vascular protective effects of ethanolic extract of dried fruit of Crataegus pinnatifida, hawthorn (Shan Zha), in dietinduced hypercholesterolaemic rat model. J Funct Foods 5 , $1326-1335$.

47. Kristensen M, Jensen MG, Aarestrup J, et al. (2012) Flaxseed dietary fibers lower cholesterol and increase fecal fat excretion, but magnitude of effect depend on food type. Nutr Metab 9, 8 .

48. Caimari A, Puiggros F, Suarez M, et al. (2015) The intake of a hazelnut skin extract improves the plasma lipid profile and reduces the lithocholic/deoxycholic bile acid faecal ratio, a risk factor for colon cancer, in hamsters fed a high-fat diet. Food Chem 167, 138-144.

49. Dominguez-Avila JA, Wall-Medrano A, Velderrain-Rodriguez GR, et al. (2017) Gastrointestinal interactions, absorption, splanchnic metabolism and pharmacokinetics of orally ingested phenolic compounds. Food Funct 8, 15-38.

50. Zhang L, Zhou M, Fang G, et al. (2013) Hypocholesterolemic effect of capsaicinoids by increased bile acids excretion in ovariectomized rats. Mol Nutr Food Res 57, 1080-1088.

51. McOrist AL, Miller RB, Bird AR, et al. (2011) Fecal butyrate levels vary widely among individuals but are usually increased by a diet high in resistant starch. $J$ Nutr 141, 883-889.

52. Paturi G, Butts CA, Monro JA, et al. (2012) Evaluation of gastrointestinal transit in rats fed dietary fibres differing in their susceptibility to large intestine fermentation. J Funct Foods $\mathbf{4}$, $107-115$

53. Hu Y, Le Leu RK, Christophersen CT, et al. (2016) Manipulation of the gut microbiota using resistant starch is associated with protection against colitis-associated colorectal cancer in rats. Carcinogenesis 37, 366-375.

54. Rodriguez-Cabezas ME, Camuesco D, Arribas B, et al. (2010) The combination of fructooligosaccharides and resistant starch shows prebiotic additive effects in rats. Clin Nutr 29, 832-839.

55. Fonteles TV, Leite AK, Silva AR, et al. (2016) Ultrasound processing to enhance drying of cashew apple bagasse puree: influence on antioxidant properties and in vitro bioaccessibility of bioactive compounds. Ultrason Sonochem 31, 237-249.

56. Liu C, Zheng Y, Xu W, et al. (2014) Rhubarb tannins extract inhibits the expression of aquaporins 2 and 3 in magnesium sulphate-induced diarrhoea model. Biomed Res Int 2014, 619465.

57. Hu JL, Nie SP, Min FF, et al. (2012) Polysaccharide from seeds of Plantago asiatica L. increases short-chain fatty acid production and fecal moisture along with lowering $\mathrm{pH}$ in mouse colon. J Agric Food Chem 60, 11525-11532.

58. Yasmin A, Butt MS, Afzaal M, et al. (2015) Prebiotics, gut microbiota and metabolic risks: Unveiling the relationship. J Funct Foods 17, 189-201.

59. Salazar N, Dewulf EM, Neyrinck AM, et al. (2015) Inulin-type fructans modulate intestinal Bifidobacterium species populations and decrease fecal short-chain fatty acids in obese women. Clin Nutr 34, 501-507.

60. Louis P, Hold GL \& Flint HJ (2014) The gut microbiota, bacterial metabolites and colorectal cancer. Nat Rev Microbiol 12, 661-672.

61. Massot-Cladera M, Costabile A, Childs CE, et al. (2015) Prebiotic effects of cocoa fibre on rats. J Funct Foods 19 , 341-352.

62. Delgado GTC, Tamashiro WMSC \& Pastore GM (2010) Immunomodulatory effects of fructans. Food Res Int 43, 1231-1236.

63. Bondonno NP, Bondonno CP, Ward NC, et al. (2017) The cardiovascular health benefits of apples: whole fruit vs. isolated compounds. Trends Food Sci Technol (epublication ahead of print version 30 October 2017). 
64. Perry J \& Ying W (2016) A review of physiological effects of soluble and insoluble dietary fibers. J Nutr Food Sci 6, 476.

65. Mildner-Szkudlarz S \& Bajerska J (2013) Protective effect of grape by-product-fortified breads against cholesterol/cholic acid diet-induced hypercholesterolaemia in rats. J Sci Food Agric 93, 3271-3278.

66. Uebelhack R, Busch R, Alt F, et al. (2014) Effects of cactus fiber on the excretion of dietary fat in healthy subjects: a double blind, randomized, placebo-controlled, crossover clinical investigation. Curr Ther Res Clin Exp 76, 39-44.

67. Jump DB, Depner CM, Tripathy S, et al. (2016) Impact of dietary fat on the development of non-alcoholic fatty liver disease in Ldlr-/- mice. Proc Nutr Soc 75, 1-9.

68. Das N, Mandala A, Bhattacharjee S, et al. (2017) Dietary fat proportionately enhances oxidative stress and glucose intolerance followed by impaired expression of the genes associated with mitochondrial biogenesis. Food Funct 8, $1577-1586$.

69. Cho SJ, Park HJ, Jung UJ, et al. (2014) The beneficial effects of combined grape pomace and omija fruit extracts on hyperglycemia, adiposity and hepatic steatosis in $\mathrm{db} / \mathrm{db}$ mice: a comparison with major index compounds. Int J Mol Sci $\mathbf{1 5}$, 17778-17789.
70. Quinones M, Miguel M \& Aleixandre A (2013) Beneficial effects of polyphenols on cardiovascular disease. Pharmacol Res 68, 125-131.

71. Kim YS \& Ho SB (2010) Intestinal goblet cells and mucins in health and disease: recent insights and progress. Curr Gastroenterol Rep 12, 319-330.

72. Zhang S, Zheng L, Dong D, et al. (2013) Effects of flavonoids from Rosa laevigata Michx fruit against high-fat diet-induced nonalcoholic fatty liver disease in rats. Food Chem 141, 2108-2116.

73. Paim RTT, Benjamin SR, Rondina D, et al. (2017) Antihypercholesterolemic effects of fruit aqueous extract of Copernicia prunifera (Miller) H. E. Moore in mice dietinduced hypercholesterolemia. Evid Based Complement Alternat Med 2017, 1-15.

74. Pereira RR, de Abreu IC, Guerra JF, et al. (2016) Acai (Euterpe oleracea Mart.) upregulates paraoxonase 1 gene expression and activity with concomitant reduction of hepatic steatosis in high-fat diet-fed rats. Oxid Med Cell Longev 2016, 1-13.

75. Pérez-Beltrán YE, Becerra-Verdín EM, Sáyago-Ayerdi SG, et al. (2017) Nutritional characteristics and bioactive compound content of guava purees and their effect on biochemical markers of hyperglycemic and hypercholesterolemic rats. J Funct Foods 35, 447-457. 